Public-data File 91-30

\title{
LABORATORY PROCEDURES FOR PROCESSING TEPHAA SAMPLES
}

\author{
by \\ DeAnne S. Pinney \\ Alaska Dlvision of \\ Geological and Geophysical Surveys
}

\begin{abstract}
August 1991
THIS REPORT HAS NOT BEEN REVIEWED FOR TECHNICAL CONTENT (EXCEPT AS NOTED IN

TEXT) OR FOR CONFORMITY TO THE

EDITORIAL STANDARDS OF DGGS.
\end{abstract}

794 University Avenue, Sulte 200

Fairbanks, Alaska $99709-3645$ 


\title{
LABORATORY PROCEDURES FOR PROCESSING TEPHRA SAMPLES
}

By

\author{
DeAnne S. Pinney ${ }^{1}$
}

CONTENTS

Introduction. 1

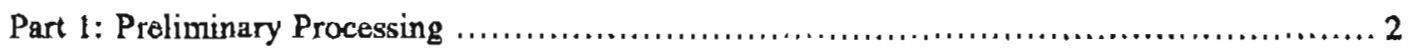

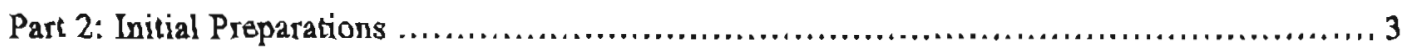

Part 3: Removing Cement and Contaminants........................................... 4

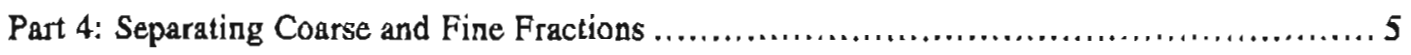

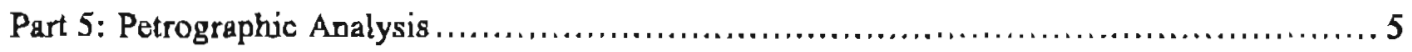

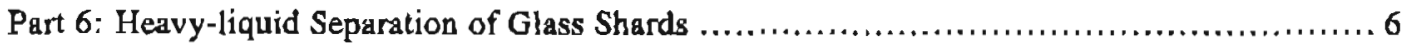

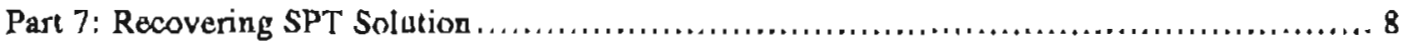

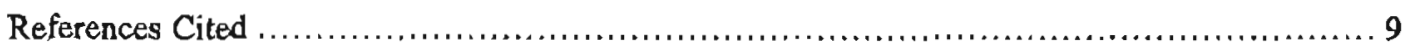

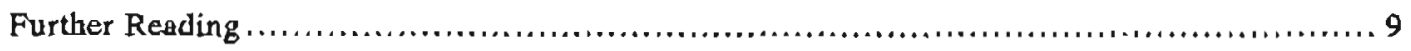

FIGURES

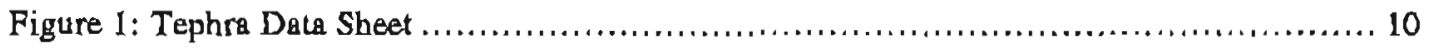

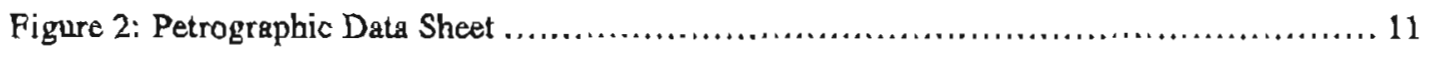

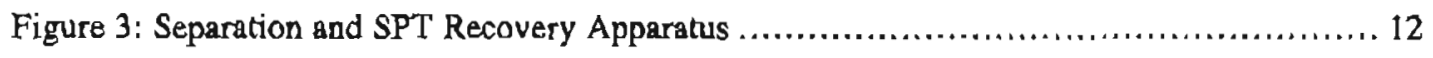

\section{INTRODUCTION}

This report is a step-by-step guide to processing tephra samples for petrographic and geochemical analysis using laboratory facilities of the Fairbanks branch of the Alaska Division of Geological and Geophysical Surveys (ADGGS). Preparation procedures are modified from Steen-MoIntyre (1977), and

${ }^{1}$ Alaska Division of Geological and Geophysical Surveys 
glass separation techniques using sodium polytungstate are modeled after Savage's (n,d.) work with conodont separations.

\section{PART 1: PRELIMINARY PROCESSING}

1) Record stratigraphic and geographic information on Tephra Data Sheet (TDS) (Figure 1)

2) Label drying containers (aluminum pans for large samples, plastic evaporating dishes for small samples) with appropriate sample numbers

3) Transfer samples to labeled containers, cover loosely witb paper towels to protect from contamination, and allow to air dry; samples may also be dryed in oven with very low heat

4) Weigh and record weight on TDS; transfer samples to vials labeled with sample numbers

5) Prepare temporary grain mounts of fine grained samples and examine for glass using petrographic mictoscope:

a) use slide from box marked "Reuseable Slides"

b) shake vial to homogenize tephra and use small spatula to transfer small amount of sample to slide

c) carefully place square $18 \times 18 \mathrm{~mm}$ cover glass over sample on slide

d) place drops of refractive index oil or vegetable oil at margin of cover glass and allow capillary action to draw oil beneath cover glass

e) place finger on cover glass and move gently in circular fashion to distribute sample in oil

f) place slide on microscope stage and examine for glass; with polars crossed and gypsum plate in, glass will appear as red or magenta fragments the same color as the oil and will not change color as stage is rotated (isotropic)

g) determine if sample is a tephra; heavily contaminated samples, particularly those recovered from eolian silt, may show very few glass shards and collector/operator judgement must be used to determine if sample warrants further treatment as a tephra

h) samples determined not to be tephras are labeled NAT (Not A Tephra) on TDS and sample vial, and archived; no further analysis

i) discard used cover glasses; wash slides for reuse 


\section{PART 2: INITIAL PREPARATIONS}

1) Separate fraction to be analyzed:

a) coarse pumice: select at least five clasts; break into pieces using hammer or mortar/pestle; select pieces from clast interiors; crush (do not grind) to completely pass through 60-mesh screen (wetsieve over sediment trap using 60- and 230-mesh screens); transfer -60 -to- +230 -mesh fraction to beaker labeled with sample number

b) medium pumice (lapilli): select at least ten lapilli; crush (do not grind) to completely pass through 60-mesh screen (wet-sieve as in " $\mathrm{a}$ "); transfer -60-to- +230 -mesh fraction to beaker labeled with sample number

c) fine ash: shake sample vial well to homogenize sample and transfer at least $10 \mathrm{ml}$ (if possible) to beaker labeled with sample number; if initial petrographic examination showed little glass, commensurately more sample is necessary to recover sufficient glass for analysis

***) for all samples, try to retain at least one-half of total sample as bulk raw material to be archived for future reference, further analysis (such as textural analysis), or in the event of loss or contamination of the initial analysis fraction (this may not be possible for some small-volume fine-grained samples, but always retain some material in raw form)

2) Sonically clean analysis fractions:

a) add water to samples until beakers are full

b) place beakers in sonic cleaner basin and fill basin with water to approximately same level as water in beakers; do not overfill

c) sonically clean samples 10 to 15 minutes, stirring occasionally; be sure to rinse stirring rod well between samples

d) remove sample beakers from basin and wet-sieve contents over sediment trap using 230-mesh screen; transfer +230 -mesh fraction back to labeled beakers and decant excess water

***) always wear ear protection when sonic cleaner is in use, and keep lab door closed to protect others 


\section{PART 3: REMOVING CEMENT AND CONTAMINANTS}

1) If present, treat samples for organics (rootlets, disseminated organic material):

a) prepare boiling water bath in hood with fan on

b) add several times ( 4 to 6 ) the sample volume of household bleach to each sample beaker and geatly swirl to mix

c) using clothes-pins, affix beakers to inner sides of pan containing boiling water, keeping beakers suspended off pan boltom

d) keep sample beakers immersed in bath for 10 to 15 minutes

e) remove beakers and carefully fill with water to dilute bleach; allow to sit for several minutes, then decant liquid and suspended material into drain; repeat rinse

f) bleach treatment procedure may be repeated if necessary

g) if bleached organic fragments persist after second treatment, process as for iron cement even if no iron is present (see "2")

h) fill beakers with water and sonically clean 5 to 10 minutes

2) If present, treat for iron stains/cements (sample has yellow-to-orange-to-red discoloration):

a) set hot plate on lowest setting in hood with fan on and water running in drain

b) add several times ( 3 to 5) the sample volume of $6 \mathrm{~N}$ hydrochloric acid to each sample beaker and gently swirl to mix

c) place sumple beakers on hot plate to gently warm for about 2 to 4 minutes (no longer), swirling occasionally to mix

d) remove beakers from heat and carefully fill with water to dilute acid; allow to sit for several minutes, then carefully decant liquid and suspended material into drain in which water is running; repeat rinse twice more

e) fill beakers with water and sonically clean 5 to 10 minutes

***) keep water runuing in drain for at least 15 minutes after last acid is discarded into drain to dilute the acid and thouroghly flush the drainage system 


\section{PART 4: SEPARATING COARSE AND FINE FRACTIONS}

1) Wet-sieve samples over sediment trap using 60- and 230-mesh screens, rinsing well; transfer +60 mesh fractions to disposable evaporating dishes labeled with sample numbers and suffix " $b$ ", and -60 to- +230 -mesh fractions to disposable evaporating dishos labeled with sample numbers and suffix " $\mathrm{a}$ "; decant excess water

2) Allow samples to air dry, or dry in oven with very low heat

3) Transfer coarse fraction "b" to vials labeled with sample numbers and suffix "b" and archive; no further analysis (remember that coarse- and medium-grained samples will not have "b"-vials as their analysis fractions were crushed to pass through 60-mesh screen)

4) Transfer fine fruction " $a$ " 10 vial labeled with sample numbers and suffix " $a$ "

\section{PART 5: PETROGRAPHIC ANALYSIS}

1) Prepare permanent grain mounts of tephras using cleaned "a" fractions:

a) label clean $1 \times 3^{\circ}$ slides with sample numbers and arrange on paper towels next to corresponding sample vials (approximately 20 grain mounts can be made at one time, if one works quickly)

b) mix package of Buehler Epo-mix Epoxide according to instructions; wear protective gloves and avoid inbaling fumes; work quickly from this point onward (epoxy sets up fast!)

c) dispense sufficient epoxy on each slide such that, when cover glass is ultimately pressed down, epoxy will spread beneath entire area of cover glass without much excess squeezing out (this will take practice)

d) shake sample vial to homogenize tephra, then use small spatula or flattened toothpick to sprinkle some sample over epoxy; wipe instrument carefully between samples to avoid contamination

e) using separate toothpick for each sample, carefully mix tephra into epoxy using circular and sideto-side motions; avoid introducing air bubbles into epoxy

f) place $24 \times 60 \mathrm{~mm}$ rectangular cover glass over epoxy/tephra mixture and press gently to squeeze out excess; a toothpick or strip of stiff paper may be used to scoop excess epoxy from margins of slide 
g) petrographic examination may be carried out after one hour if desired; allow at least one day for epoxy to cure completely before putting grain mounts in labeled slots in slide boxes

2) Characterize tephras petrographically and record on Petrographic Data Sheet (PDS) (Figure 2) labeled with sample numbers:

a) coarse- and medium-grained tephras: note color of glass, presence of inclusions and vesicles; point count mafic minerals; note unusual minerals and mineral characteristics

b) fine-grained tephras: note color of glass, shard morphology, presence of inclusions and vesicles, relative abundance of glass shards; point count only mafic minerals with attached glass; note unusual minerals and mineral characteristics (only for minerals with attached glass)

\section{PART 6: HEAVY-LIQUID SEPARATION OF GLASS SHARDS}

1) Separations are performed on fine "a" fraction

2) Set up separatory equipment as illustrated in Figure 3; four samples may be run simultaneously using this apparatus

3) Fold and label in pencil two $15-\mathrm{cm} / 4$ filter-paper circles for each sample: sample number and " $g$ " (glass) on one, and sample number and "h" (heavies) on the other

4) Place papers in filter funnels; place filter funnels in bottles; arrange funnel/bottle units with "heavies" beneath separatory funnels and "glass" to the side

5) Prepare sodium polytungstate (SPT) solution with specific gravity 2.42 (the following will produce sufficient solution to perform approximately eight separations):

a) carefully place calibrated glass density floats into $500 \mathrm{~mL}$ glass beaker (white with orange and black markings $=$ spg 2.4250 , red with black markings $=$ spg 2.4150); the floats are fragile, expeusive, and difficult to replace, so handle gently

b) add approximately $250 \mathrm{~mL}$ distilled water to beaker 
c) wearing dust mask and gloves*, add SPT powder to water while stirring gently with plastic stirring rod until red float just rises to surface and white float remains at bottom of beaker (SPT solution should be at approximately the 350-mL-mark); as proper density is appronched, allow solution to sit a minute or two after each addition to allow powder to pass completely into solution (mixture will clarify when solid is dissolved); if density is overshot and white float rises, add very small amounts of distilled water from a wash bottle and mix well between additions until white float sinks completely to bottom

d) when proper density has been achieved, use flattened end of plastic stirring rod to carefully slide red float up beaker side and into plastic dish containing sufficient distilled water to completely immerse float; keep white float in solution beaker as check against density increases via evaporation of water - if float rises, adjust density with distilled water as explained in "c"

6) Shake sample vial to homogenize tephra; make certain stopcock is closed and place approximately one teaspoon of sample in separatory funnel; be sure to retain some "a" fraction in vial for archiving

7) Add a small amount (about $15 \mathrm{ml}$ ) of SPT solution to separatory funnel, close top ard shake vigorously to mix; open funnel top and, holding funnel at an angle and rotating slowly, carofully pour a thin stream of SPT solution down the side of the funnel to rinse particles from funnel walls; total amount of SPT solution used for a one-teaspoon sample generally averages approximately $40 \mathrm{ml}$

8) Close separatory funrel top and retum to rack; allow to sit undisturbed 10 to 15 minutes (minimum)

9) Be certain sample number of tephra in separatory funnel matches that of labeled filter papers in filter fungels

10) Remove top of separatory funnel and open stopcock; allow SPT solution and heavy fragments to collect in "heavies" filter; close stopcock after heavies have drained from separatory funnel, but well before the floating glass fraction begins to pass through the stopcock; remaining solution depth in neck of separatory funnel shouid be no less than 40 to $50 \mathrm{~mm}$

*SPT is considered non-toxic, so these precautions are optional; nevertheless, SPT powder is very fine and, as with other dusts, one should avoid inhaling excess amounts during mixing 
11) Remove "hesvies" funnel/bottle unit and replace with corresponding "glass" unit; drain remaining solution into filter paper and rinse interior of separatory funnel using wasb bottle of distilled water; collect as much glass clinging to funnel walls as possible

12) Thoroughly rinse "heavies" and "glass" fractions many times with distilled water from wash bottle, making certain to saturate filter paper each time; it is imperative that separates be absolutely rinsed clean of SPT, as it dries to a hard cement that may be difficult to dissolve once dry

13) Remove filter papers containing separates from funnels and allow to air dry, or dry in oven with very low heat

14) When completely dry, transfer separates to labeled vials; "heavies" fraction vials are labeled with sample numbers and suffix " $h$ ", "glass" fraction vials with sample numbers and suffix " $g$ "

\section{PART 7: RECOVERING SPT SOLUTION}

1) Fold a $27-\mathrm{cm} \$ 1$ filter paper circle and place in large filter funnel draining into 10 liter carboy

2) Pour used SPT solution collected from separations into filter paper and allow to drain; the paper is slow and filtering may take up to 30 minutes

3) Pour filtered SPT solution into teflon evaporating dishes and place in drying oven that has been heated to between 60 and $80^{\circ} \mathrm{C}$

4) Allow SPT solution to reduce to approximately $1 / 3$ original volume; do not allow SPT solution to evaporate to complete dryness

5) Pour recovered SPT solution into bottle labeled "Recovered SPT Solution" and seal tightly

6) When reusing SPT solution, density may be adjusted downward by adding distilled water or upward by further evaporation or addition of SPT solid 


\section{REFERENCES}

Savage, N.M., n.d., The use of sodium polytungstate for conadont separations: unpublished report, 6 p. Steen-MacIntyre, Virginia, 1977, A manual for tepbrochronology: Virginia Steen-MacIntyre, Idaho Springs, Colorado, $167 \mathrm{p}$.

\section{FURTHER READING}

Gregory, M.R., and Johnston, K.A., 1987: A nontoxic substitute for hazardous heavy liquids - aqueous sodium polytungstate $\left(3 \mathrm{Na}_{2} \mathrm{WO}_{4} \cdot 9 \mathrm{WO}_{3} \cdot \mathrm{H}_{2} \mathrm{O}\right)$ solution (Note): New Zealand Journal of Geology and Geophysics, v. 30 , p. $317-320$. 


\section{TEFMRA DATA OHEET}

Field Sample No

Date Submitted

Collector

Location

Description of Tephra (color, thickness, grain size)

Comments

Special Procedures: organics iron axides other
Date Collected

Microprobe Laboratory

Operator Name

Geochemistry
Population 1 ( $n=\ldots$

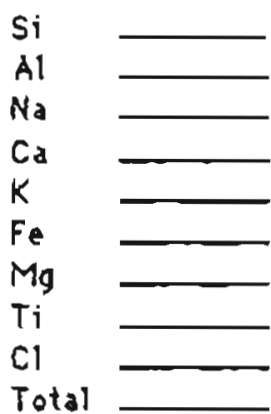
mean standard deviation

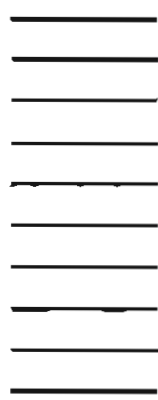

Submittor

Address
Stratigraphic Setting: General Sketoh (include dates )

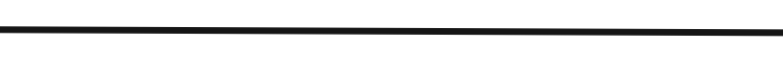


Eigure 2: Petrographic daca sheer (sample)

\section{PETROGRAPHUE DATA SHEET}

Operator Name

Date

Field Sample No

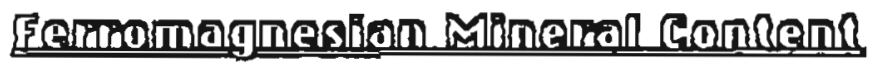

Orthopyroxene

Totel

Clinopyroxene

Total

Hornblende (green)

Totol

Hornblende (brown)

Total

Biotite

Total

Other

Total

Totol

ณกลง

Sherd Morphology

Inclusions?

Vesicles?

Other? Describe

\section{COMIMIINIIS:}




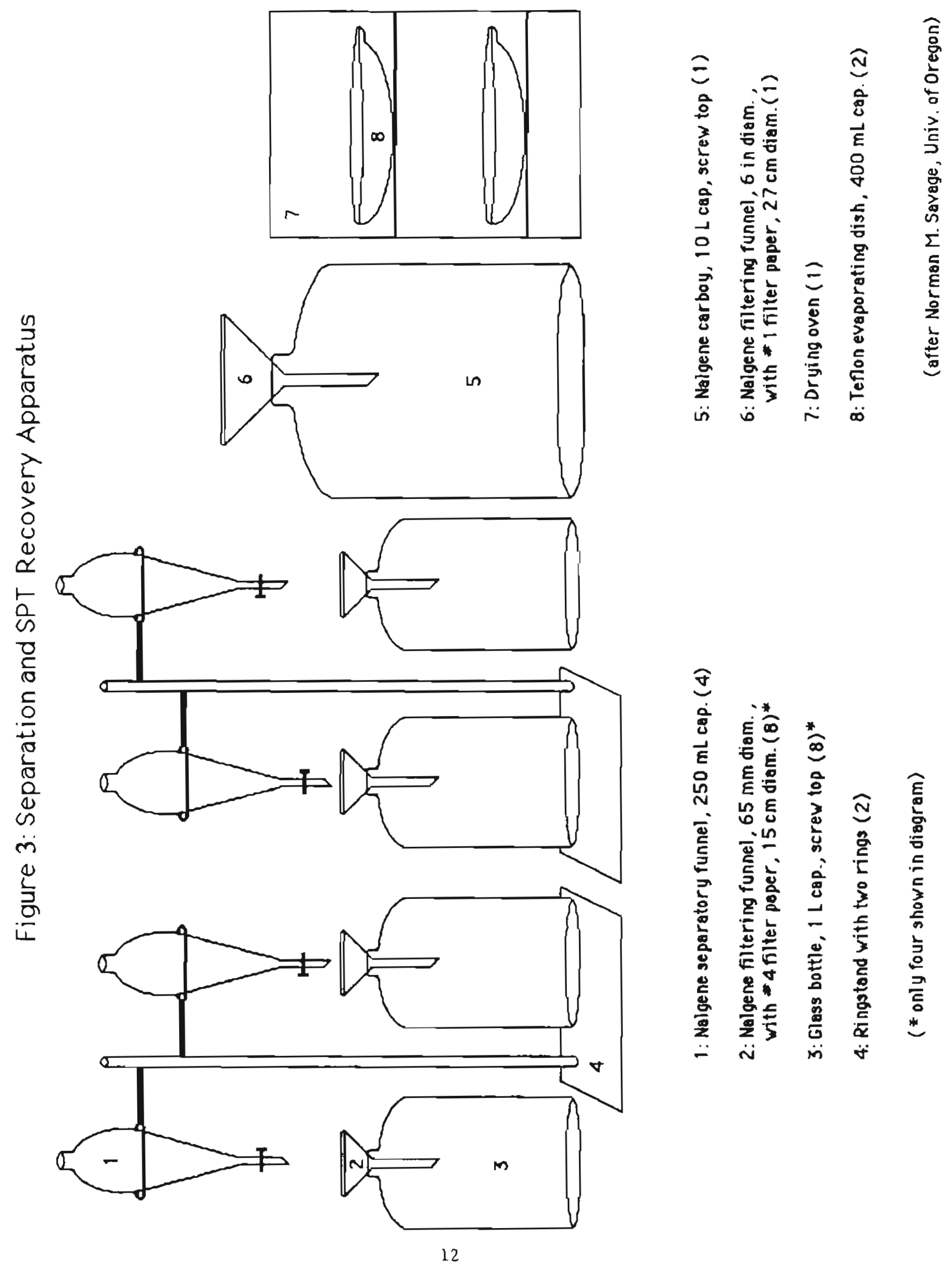

